\title{
Cross-cultural adaptation and measurement properties of generic and cancer-related patient-reported outcome measures (PROMs) for use with cancer patients in Brazil: a systematic review
}

\author{
Carlos Augusto Albach ${ }^{1}$ Richard Wagland ${ }^{2} \cdot$ Katherine J. Hunt $^{2}$
}

Accepted: 2 September 2017/ Published online: 8 September 2017

(c) The Author(s) 2017. This article is an open access publication

\begin{abstract}
Purpose This systematic review (1) identifies the current generic and cancer-related patient-reported outcome measures (PROMs) that have been cross-culturally adapted to Brazilian Portuguese and applied to cancer patients and (2) critically evaluates their cross-cultural adaptation (CCA) and measurement properties.

Methods Seven databases were searched for articles regarding the translation and evaluation of measurement properties of generic and cancer-related PROMs crossculturally adapted to Brazilian Portuguese that are applied in adult ( $\geq 18$ years old) cancer patients. The methodological quality of included studies was assessed using the COSMIN checklist.

Results The bibliographic search retrieved 1674 hits, of which seven studies analysing eight instruments were included in this review. Data on the interpretability of scores were poorly reported. Overall, the quality of the CCA process was inconsistent throughout the studies. None of the included studies performed a cross-cultural
\end{abstract}

Electronic supplementary material The online version of this article (doi:10.1007/s11136-017-1703-5) contains supplementary material, which is available to authorized users.

Carlos Augusto Albach

caa1n14@soton.ac.uk

Richard Wagland

R.Wagland@soton.ac.uk

Katherine J. Hunt

K.J.Hunt@soton.ac.uk

1 Faculty of Health Sciences, University of Southampton, University Road, Southampton, Hampshire SO17 1BJ, UK

2 Faculty of Health Sciences, University of Southampton, Highfield, Southampton, Hampshire SO17 1BU, UK validation. The evidence concerning the quality of measurement properties is limited by poor or fair methodological quality. Moreover, limited information regarding measurement properties was provided within the included papers.

Conclusions This review aids the selection process of Brazilian Portuguese PROMs for use in cancer patients. After acknowledging the methodological caveats and strengths of each tool, our opinion is that for quality of life and symptoms assessment the adapted FACT-G version and the ESAS could be recommended, respectively. Future research should rely on the already accepted standards of CCA and validation studies.

Keywords Patient-reported outcome measures - Brazil · Portuguese - Cancer - Cross-cultural adaptation · Measurement properties

\section{Introduction}

Patient-reported outcome measures (PROMs) are a method for ascertaining patients' views of their symptoms, functional status and health-related quality of life (HRQoL), and are useful in research to identify the subjective impact of medical or psychosocial interventions upon patients. Recently in the US and the UK, PROMs have been used to assess and compare health outcomes achieved by different healthcare providers [1]. Currently, health-related PROMs (HR-PROMs) are widely used and have a well-established role in clinical practice, research, audit and health policy. Measuring patients' subjective health status and quality of life (QoL) has also become increasingly important as life expectancy has risen in developed and underdeveloped countries, increasing the prevalence of chronic disease. 
Today, cardiovascular disease and cancer are the most common causes of death in Brazil [2], with 596,000 new cancer cases expected in 2016 [3]. Moreover, cancer patients frequently have long and complex disease trajectories making measurement of patient-reported and clinical outcomes equally important.

PROM is an umbrella term for the vast range of healthrelated questionnaires that are completed by patients. Generic PROMs are tailored to assess relevant health domains to all individuals, thus allowing comparisons of health status between different populations and disease groups [4]. Similarly, cancer-related PROMs can be applied across distinct tumour types. Whenever possible, the use of an existing validated PROM is preferred rather than developing a new scale [5]. However, most instruments have been developed and validated in Englishspeaking populations [6, 7], so many have subsequently been adapted for other languages and cultures.

Cross-cultural adaptation (CCA) and validation (CCV) of PROMs is a contentious issue due to various possible methodological approaches [8]. Epstein et al. differentiate the term translation (the production of a document from a source to a target language) from CCA (a process that ensures equivalence in meaning) [8]. CCV could be described as 'the degree to which the performance of the items on a translated or culturally adapted PROM instrument is an adequate reflection of the original version of the PROM' [9]. A well-conducted CCA is critical to ensure a good methodological quality of CCV. There has been a growing interest in cross-culturally adapted and validated HR-PROMs for use in multinational trials recruitment and external validation of effectiveness studies [10].

Portuguese ranks sixth as the most international language, with 206 million native Portuguese speakers worldwide [11], the majority of them in Brazil. In 2007, 1.2 million Brazilians lived in the United States and an additional 2.8 million people were living outside America [12]. There are an increasing number of PROMs available in Brazilian Portuguese, providing a wide choice in the selection of suitable instruments. Whilst systematic reviews of HR-PROMS are recognised as valuable to aid in the selection of robust instruments [13], there has only been one review assessing CCA of Brazilian Portuguese PROMs focused solely on shoulder disability. The authors highlighted a lack of robust critical evaluation of instruments in Brazil [14]. The objectives of this systematic review, therefore, are to identify generic and cancer-related PROMs that have been cross-culturally adapted to Brazilian Portuguese and assessed for use with cancer patients, and to critically appraise the quality of CCA and measurement properties of translated versions with a view at informing potential users both in clinical research and in practice settings.

\section{Methods}

\section{Search strategy}

The search for articles was performed using an adapted strategy that involved the combination of free text search terms, medical subject headings (MeSH) for terms in English, health sciences descriptors for terms in Portuguese (including patient-reported, quality of life, cancer, crosscultural, language, Brazil and Portuguese) and the Boolean operators 'OR', 'AND' and 'NOT' [15]. The following databases were searched: MEDLINE (OVID, 1946 onwards), EMBASE (OVID, 1947 onwards), PsycINFO (EBSCO, 1800 s onwards), CINAHL Plus (EBSCO, 1937 onwards) and Scopus (1960 onwards). For Latin America databases SciELO (Web of Science) and LILACS, the same text words were used, albeit in Portuguese. All databases were set up to run a new search every week until the 1st of June 2016. The MEDLINE (OVID) search strategy is included in Online Resource 1. The strategy was adapted to the syntax of other databases and is available upon request. The reference list of included studies was manually scanned for additional studies.

Results from the literature search were uploaded to EndNote software v.7.5 (Thomson Reuters ${ }^{\circledR}$ ) by the lead reviewer (CA) and were assessed for eligibility by the second reviewer ( $\mathrm{RW})$, differences being resolved in discussion with a third reviewer $(\mathrm{KJH})$. Duplicated hits were excluded, and the remaining records were screened by title and abstract. All studies deemed to be eligible had their full text obtained. The reasons for exclusion were recorded. A maximum of two e-mail attempts to contact authors were made to collect any missing information.

\section{Selection criteria}

A study was considered eligible if it met the following inclusion criteria: original article (e.g. not a conference abstract, review or editorial), published in English or Portuguese, aimed primarily at evaluating the measurement properties of a generic or cancer-related PROM adapted to Brazilian Portuguese for use with adult ( $\geq 18$ years old) cancer patients in clinical trials or in oncology care delivery. There were no restrictions concerning primary site or stage of disease, treatment, gender or other clinical or epidemiological characteristics. Publications describing solely the CCA process were excluded, as well as studies reporting on disease-specific PROMs other than cancer and domain-specific questionnaires. 


\section{Data collection and critical appraisal of eligible studies}

The following data of the included studies were extracted: year of publication, inclusion and exclusion criteria, sample size, PROM used, full-text availability of the tool, number of items of the instrument and the reported time to complete the questionnaire. The epidemiological and clinical characteristics of the subjects included in each study (age, gender, cancer stage, disease status, treatment received and setting) were extracted. Information relevant to the interpretability of the instrument (percentage of missing items, distribution of scores and percentage of the respondents who had the highest and lowest possible scores) was collected.

The CCA quality was independently assessed by both $\mathrm{CA}$ and RW, based on the stages described by Beaton et al. [16] (Fig. 1). Table 1 shows the rating method for quality assessment of CCA [7]. The original study that described the full CCA process was retrieved and evaluated when the CCA and the measurement properties of the same PROM involved separate publications.

The measurement properties described in all eligible studies were first identified using the taxonomy recommended by Mokkink et al. [9]. Methodological quality of included studies was assessed using the COnsensus-based Standards for the selection of health Measurement INstruments (COSMIN) scale [17, 18]. The scale has previously been used in validation studies [19] and systematic reviews of PROMs [20, 21]. The checklist contains twelve boxes. Boxes A to I contain standards for studies on measurement properties. Four different answer options for each item of boxes A to I are possible (excellent, good, fair and poor), representing the methodological quality of that specific item. Finally, a methodological quality score per box is achieved by selecting the lowest rating of any item in a box. The full-text score system is available at www. cosmin.nl.

Finally, measurement properties from each adapted PROM were independently graded by $\mathrm{CA}$ and RW as positive, indeterminate or negative based on pre-specified criteria [22, 23] (Table 2), again with disagreements resolved by $\mathrm{KJH}$.

\section{Results}

The database search resulted in 1674 records (Fig. 2). The first, automatic round of duplicates screening removed 159 records. Hence, 1515 records remained to be analysed by title and abstract, of which 1239 records were excluded mainly because the paper did not describe the use of a cross-culturally adapted PROM in Brazilian cancer patients or the study was not concerned with PROMs at all. Then, 276 records were submitted to a manual analysis of duplicated hits, resulting in 147 redundant records. Finally, 129 studies had their full text analysed against the inclusion and exclusion criteria: 122 studies were excluded and seven studies met the inclusion criteria following full-text review. Online Resource 2 details the excluded studies
Fig. 1 Recommended stages for cross-cultural adaptation (adapted from Beaton et al. [16])

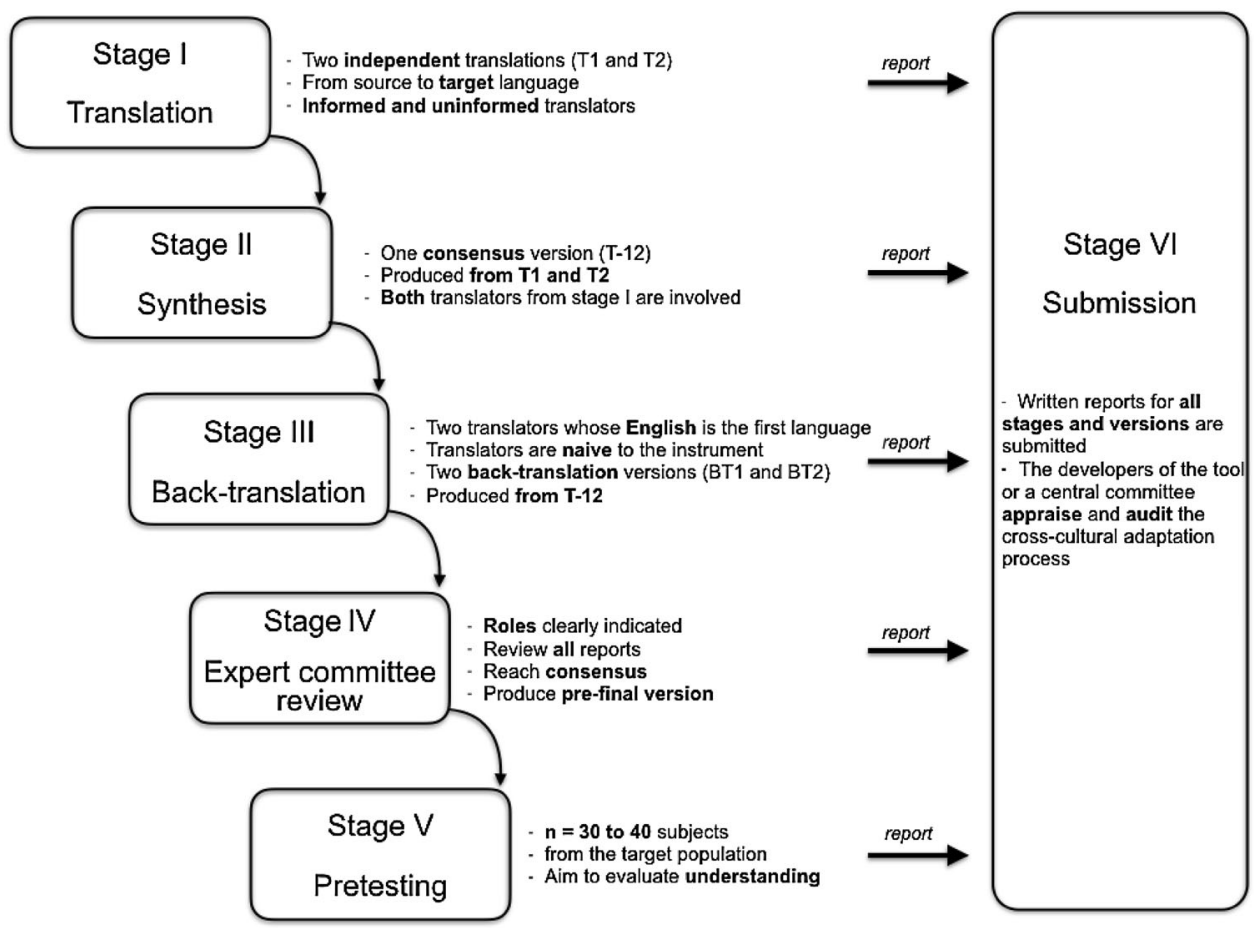


Table 1 Quality criteria of the cross-cultural adaptation process (adapted from Oliveira et al. [7])

\begin{tabular}{|c|c|c|}
\hline Stage & Rating $^{\mathrm{a}}$ & Quality criteria \\
\hline \multirow[t]{4}{*}{ I: Forward translation } & + & Translations conducted by two or more independent translators \\
\hline & $?$ & $\begin{array}{l}\text { Doubtful translation process (e.g. translators' background or awareness status about the tool are different from } \\
\text { the recommended, translation conducted by one translator) }\end{array}$ \\
\hline & - & Translation conducted by two non-independent translators \\
\hline & 0 & No information on the forward translation process \\
\hline \multirow[t]{3}{*}{ II: Synthesis } & + & Synthesis conducted by the same two or more translators from stage I \\
\hline & $?$ & Doubtful synthesis process (e.g. different translators or professionals from stage I) \\
\hline & 0 & No information on the synthesis process \\
\hline \multirow[t]{4}{*}{ III: Back-translation } & + & $\begin{array}{l}\text { Back-translation made by two or more independent translators for whom English is the first language and who } \\
\text { are naive to the instrument }\end{array}$ \\
\hline & $?$ & $\begin{array}{l}\text { Doubtful back-translation process (e.g. English is not the translators' first language or they are aware of the } \\
\text { instrument, back-translation conducted by one translator only) }\end{array}$ \\
\hline & - & Back-translation made by two non-independent translators \\
\hline & 0 & No information on back-translation process \\
\hline \multirow[t]{4}{*}{$\begin{array}{l}\text { IV: Expert committee } \\
\text { review }\end{array}$} & + & $\begin{array}{l}\text { An expert committee is reported and participants' roles clearly indicated. The committee reviews all } \\
\text { documents }\end{array}$ \\
\hline & $?$ & Doubtful expert committee review (e.g. there is no mention of participants' roles) \\
\hline & - & The committee reviews only one or some documents \\
\hline & 0 & No information on expert committee \\
\hline \multirow[t]{4}{*}{ V: Pretesting } & + & Pretest was conducted in 30 or more subjects from the target population \\
\hline & $?$ & Doubtful design (e.g. there is no mention of the number of subjects tested, target population not described) \\
\hline & - & Pretest was conducted in less than 30 subjects \\
\hline & 0 & No information on the pretest \\
\hline \multirow[t]{3}{*}{ VI: Submission } & + & All reports and forms were submitted to the developer of the instrument or central committee for appraisal \\
\hline & $?$ & $\begin{array}{l}\text { Doubtful submission process (e.g. the reports and forms were received by others instead of the developer of } \\
\text { the instrument or central committee) }\end{array}$ \\
\hline & 0 & No information on submission process \\
\hline
\end{tabular}

${ }^{a}+$ Positive rating; ? indeterminate rating; - negative rating; 0 no information available

following full-text assessment. An Excel spreadsheet file with additional data extracted from the excluded records is available upon request.

In total, eight HR-PROMs were identified: four healthrelated QoL tools (two European Organization for Research and Treatment of Cancer QoL questionnairesEORTC QLQ-C30 [24] and EORTC QLQ-C15-PAL [25], Functional Assessment of Cancer Therapy-general or FACT-G [26] and the World Health Organization QoL questionnaire short version or WHOQOL-bref [27]); one symptom assessment tool (Edmonton Symptom Assessment System or ESAS [28]); one symptom and severity assessment tool (MD Anderson Symptom Inventory-core or MDASI [29]); one health status tool (Medical Outcomes Study 36-Item Short-Form Health Survey or SF-36 [27]) and one functional screening tool (Vulnerable Elders Survey-13 or VES-13 [30]).

Table 3 shows the general characteristics of studies. The full text of the adapted instrument was provided by only one study [28]. The average time to complete the questionnaire was described only for the ESAS [28].

Table 4 presents data relevant to the interpretability of the studies. Adequate description about how missing items were handled was found in one study [26]. Campos et al. reported the missing data to FACT-G items (i.e. the nonresponse rate) ranging from 0.1 to $0.6 \%$, except for the item related to 'satisfaction with the sex life'. This item had a non-response rate of $45 \%$ and was excluded from the final analysis after consent from the developers of the original tool. Moreover, the authors opted to exclude individuals who did not answer one or more of the other PROM items [26]. The distribution of scores was infrequently reported across studies.

Factors influencing the generalisability of the tools are presented in Table 5. All PROMs have been used with patients attending outpatient departments, while FACT-G and ESAS have also been used with inpatients [26, 28]. The EORTC QLQ-C-15 PAL was applied only in patients with advanced cancer. Limited participant description 
Table 2 Quality criteria for measurement properties of health-related questionnaires [23] (based on Terwee et al. [22])

\begin{tabular}{|c|c|c|}
\hline Property & Rating $^{\mathrm{a}}$ & Quality criteria \\
\hline \multicolumn{3}{|l|}{ Reliability } \\
\hline \multirow{3}{*}{$\begin{array}{l}\text { Internal } \\
\text { consistency }\end{array}$} & + & (Sub)scale unidimensional AND Cronbach's alpha(s) $\geq 0.70$ \\
\hline & $?$ & Dimensionality not known OR Cronbach's alpha not determined \\
\hline & - & (Sub)scale not unidimensional OR Cronbach's alpha(s) $<0.70$ \\
\hline \multirow{3}{*}{$\begin{array}{l}\text { Measurement } \\
\text { error }\end{array}$} & + & MIC $>$ SDC OR MIC outside the LOA \\
\hline & $?$ & MIC not defined \\
\hline & - & MIC $\leq$ SDC OR MIC equals or inside LOA \\
\hline \multirow[t]{3}{*}{ Reliability } & + & ICC/weighted Kappa $\geq 0.70$ OR Pearson's $r \geq 0.80$ \\
\hline & $?$ & Neither ICC/weighted Kappa nor Pearson's r determined \\
\hline & - & ICC/weighted Kappa $<0.70$ OR Pearson's $r<0.80$ \\
\hline \multicolumn{3}{|l|}{ Validity } \\
\hline \multirow[t]{3}{*}{ Content validity } & + & $\begin{array}{l}\text { The target population considers all items in the questionnaire to be relevant AND considers the questionnaire to } \\
\text { be complete }\end{array}$ \\
\hline & $?$ & No target population involvement \\
\hline & - & $\begin{array}{l}\text { The target population considers items in the questionnaire to be irrelevant OR considers the questionnaire to be } \\
\text { incomplete }\end{array}$ \\
\hline \multicolumn{3}{|l|}{ Construct validity } \\
\hline \multirow{3}{*}{$\begin{array}{l}\text { Cross-cultural } \\
\text { validity }\end{array}$} & + & Original factor structure confirmed OR no important DIF \\
\hline & $?$ & Confirmation of original factor structure AND DIF not mentioned \\
\hline & - & Original factor structure not confirmed OR important DIF \\
\hline \multirow{3}{*}{$\begin{array}{r}\text { Structural } \\
\text { validity }\end{array}$} & + & Factors should explain at least $50 \%$ of the variance \\
\hline & $?$ & Explained variance not mentioned \\
\hline & - & Factors explain $<50 \%$ of the variance \\
\hline \multirow[t]{3}{*}{$\begin{array}{l}\text { Hypothesis } \\
\text { testing }\end{array}$} & + & $\begin{array}{l}\text { (Correlation with an instrument measuring the same construct } \geq 0.50 \text { OR at least } 75 \% \text { of the results are in } \\
\text { accordance with the hypotheses) AND correlation with related constructs is higher than with unrelated } \\
\text { constructs }\end{array}$ \\
\hline & $?$ & Solely correlations determined with unrelated constructs \\
\hline & - & $\begin{array}{l}\text { Correlation with an instrument measuring the same construct }<0.50 \mathrm{OR}<75 \% \text { of the results are in accordance } \\
\text { with the hypotheses OR correlation with related constructs is lower than with unrelated constructs }\end{array}$ \\
\hline \multicolumn{3}{|l|}{ Responsiveness } \\
\hline \multirow[t]{3}{*}{ Responsiveness } & + & $\begin{array}{l}\text { (Correlation with an instrument measuring the same construct } \geq 0.50 \text { OR at least } 75 \% \text { of the results are in } \\
\text { accordance with the hypotheses OR AUC } \geq 0.70 \text { ) AND correlation with related constructs is higher than with } \\
\text { unrelated constructs }\end{array}$ \\
\hline & $?$ & Solely correlations determined with unrelated constructs \\
\hline & - & $\begin{array}{l}\text { Correlation with an instrument measuring the same construct }<0.50 \mathrm{OR}<75 \% \text { of the results are in accordance } \\
\text { with the hypotheses OR AUC }<0.70 \text { OR correlation with related constructs is lower than with unrelated } \\
\text { constructs }\end{array}$ \\
\hline
\end{tabular}

MIC minimal important change, SDC smallest detectable change, LOA limits of agreement, ICC intraclass correlation coefficient, $D I F$ differential item functioning, $A U C$ area under the curve

a + positive rating; ? indeterminate rating; - negative rating

hinders the generalisability of VES-13 and EORTC QLQC-30 [24, 30].

Table 6 shows the CCA quality of the HR-PROMs identified. No studies achieved positive ratings in more than three of the six criteria, with back-translation being the strongest single criterion amongst studies. Although the expert committee review stage was positive for two instruments (EORTC QLQ-C30 and ESAS), only the
ESAS adaptation study had the committee composition clearly described, consisting of a medical oncologist, a registered nurse, a dentist, an occupational therapist and a psychologist.

Both the methodological grade and the quality of measurement properties are presented together in Table 7. Cross-cultural validity (i.e. the equivalence of scores between the original and target populations, usually 


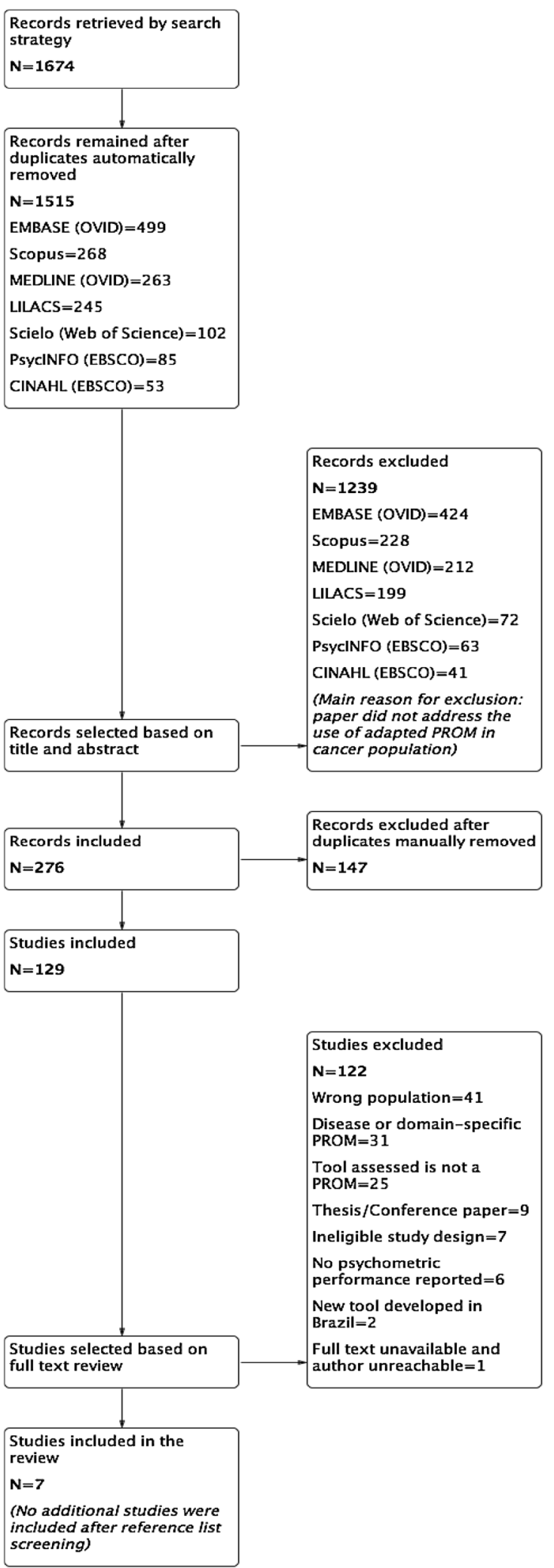

Fig. 2 Flowchart of database search strategy and selection of studies assessed by multiple group factor analysis or item response theory techniques [31]) was not reported in any study. Evidence for excellent or good methodological quality with a positive result for any measurement property was uncommon.

\section{ESAS [28]}

The CCA process scored three positive and two doubtful marks. Pretesting was negative due to the pilot test sample size $(n=24)$.

Poor methodological quality scores for reliability (testretest reliability was assessed by a second interview 4 to $96 \mathrm{~h}$ after the baseline) and responsiveness (authors provided a limited description of the measurement properties of the comparator instrument) were observed. Hypothesis testing and internal consistency were of good methodological quality.

The result for internal consistency of the tool was indeterminate (dimensionality not confirmed [37]). On the other hand, there was evidence for a positive result in hypothesis testing $(r>0.52$ for the correlation with similar items).

\section{EORTC QLQ-C30 [24]}

Back-translation and expert committee review stages of the adaptation process were positive, while pretesting was negative due to the pilot test sample size. Questionable quality was scored for forward translation and synthesis stages [36].

Good methodological quality was observed for hypothesis testing. The methodological quality of internal consistency analysis was considered poor (factor analysis was not performed and no reference to another study was provided).

Evidence for a positive result in hypothesis testing was reported $(85.1 \%$ of the previously hypothesised correlations were confirmed).

\section{EORTC QLQ-C15 PAL [25]}

The CCA methodology analysis revealed a negative score in the expert committee review. Three stages scored doubtful marks, and no information was provided about the synthesis and submission steps.

The lack of description of missing scores hindered the methodological quality for structural validity and internal consistency. A fair hypothesis testing methodology was observed as the hypothesis about expected correlations between similar instruments was not specified a priori.

The result for structural validity (confirmatory factor analysis) was indeterminate due to the absence of factors 
Table 3 Characteristics of included studies

\begin{tabular}{|c|c|c|c|c|}
\hline Instrument & $\begin{array}{l}\text { Instrument full-text } \\
\text { availability }\end{array}$ & $\begin{array}{l}\text { Instrument total number of } \\
\text { items }\end{array}$ & $\begin{array}{l}\text { Mean time to complete the } \\
\text { instrument }\end{array}$ & $\begin{array}{l}\text { Actual sample size (analysed } \\
\text { data) }\end{array}$ \\
\hline $\begin{array}{l}\text { FACT-G } \\
{[26]}\end{array}$ & $\mathrm{Yes}^{\mathrm{a}}$ & 27 & NR & 975 \\
\hline $\begin{array}{l}\text { MDASI } \\
{[29]}\end{array}$ & Yes $^{\mathrm{b}}$ & 19 & NR & 268 \\
\hline $\begin{array}{l}\text { VES-13 } \\
\text { [30] }\end{array}$ & $\mathrm{Yes}^{\mathrm{c}}$ & 13 & NR & $\begin{array}{l}272 \\
108^{d}\end{array}$ \\
\hline $\begin{array}{l}\text { EORTC QLQ-C-15- } \\
\text { PAL } \\
{[25]}\end{array}$ & No & 15 & NR & 104 \\
\hline $\begin{array}{r}\mathrm{SF}-36 \\
{[27]}\end{array}$ & No & 36 & NR & $\begin{array}{l}106 \\
99^{\mathrm{e}} \\
94^{\mathrm{f}}\end{array}$ \\
\hline $\begin{array}{l}\text { WHOQOL-bref } \\
\text { [27] }\end{array}$ & No & 24 & NR & $\begin{array}{l}106 \\
99^{\mathrm{e}} \\
94^{\mathrm{f}}\end{array}$ \\
\hline $\begin{array}{l}\text { EORTC QLQ-C30 } \\
{[24]}\end{array}$ & No & 30 & NR & 986 \\
\hline $\begin{array}{r}\text { ESAS } \\
{[28]}\end{array}$ & Yes & 10 & $2.24 \mathrm{~min}$ & $\begin{array}{l}249 \\
84^{\mathrm{g}} \\
80^{\mathrm{h}}\end{array}$ \\
\hline
\end{tabular}

\section{$N R$ not reported}

${ }^{a}$ As per request to Functional Assessment of Chronic Illness Therapy (FACIT) Group

${ }^{\mathrm{b}}$ In a separate publication [32]

${ }^{\mathrm{c}}$ In a separate publication [33]

${ }^{\mathrm{d}}$ Sample size for the reliability measurement (assessed 7 to 15 days after baseline)

${ }^{\text {e }}$ Sample size for the reliability measurement (assessed $48 \mathrm{~h}$ after baseline)

${ }^{\mathrm{f}}$ Sample size for the responsiveness measurement (assessed 30 days after baseline)

${ }^{g}$ Sample size for the reliability measurement (assessed 4 to $96 \mathrm{~h}$ after baseline)

${ }^{\mathrm{h}}$ Sample size for the responsiveness measurement (assessed $21 \pm 7$ days after baseline)

explaining variance. There was evidence for a negative result in hypothesis testing (Spearman's $r=0.30$ for the correlation of EORTC QLQ-C15-PAL emotional functioning with a similar instrument) and internal consistency (Cronbach's alpha $=0.58-0.86$ ).

\section{FACT-G [26]}

The CCA methodology has received three positive and three indeterminate marks [34].

Methodological quality of the measurement properties was rated as excellent for three out of four assessments. Few and vague hypotheses about the expected correlations of FACT-G with the EORTC QLQ-C30 were made a priori, hampering the methodological quality of hypothesis testing (construct validity).
There was evidence for a positive result in internal consistency (Cronbach's alpha $=0.71-0.82$ ). Low convergent validity was observed for the emotional and functional well-being domains. Confirmatory factor analysis provided evidence that the tool has a four-factor structure. However, the result of structural validity was indeterminate as the factors' explained variance was not mentioned.

\section{MDASI [29]}

The CCA methodology received doubtful rates in all but one step [32].

The methodological quality rate of both measurement properties assessed (structural validity and internal consistency) was fair due to the lack of description of missing scores. 
Table 4 Interpretability of included studies

\begin{tabular}{|c|c|c|c|c|c|}
\hline Instrument & Missing scores & $\begin{array}{l}\text { Description of how } \\
\text { missing items were } \\
\text { handled }\end{array}$ & $\begin{array}{l}\text { Distribution } \\
\text { of total scores }\end{array}$ & $\begin{array}{l}\text { Respondents with the } \\
\text { lowest possible total } \\
\text { score }\end{array}$ & $\begin{array}{l}\text { Respondents with the } \\
\text { highest possible total } \\
\text { score }\end{array}$ \\
\hline $\begin{array}{l}\text { FACT-G } \\
{[26]}\end{array}$ & $\begin{array}{l}0.1 \text { to } 0.6 \% \text { of non- } \\
\text { response rate per item }\end{array}$ & Yes & NR & NR & NR \\
\hline $\begin{array}{c}\text { MDASI } \\
\text { [29] }\end{array}$ & NR & NR & NR & NR & NR \\
\hline $\begin{array}{c}\text { VES-13 } \\
\text { [30] }\end{array}$ & NR & NR & NR & NR & NR \\
\hline $\begin{array}{l}\text { EORTC } \\
\text { QLQ-C- } \\
\text { 15-PAL } \\
{[25]}\end{array}$ & NR & NR & NR & NR & NR \\
\hline $\begin{array}{r}\text { SF-36 } \\
{[27]}\end{array}$ & NR & NR & Yes & Yes & Yes \\
\hline $\begin{array}{l}\text { WHOQOL- } \\
\text { bref } \\
{[27]}\end{array}$ & NR & NR & Yes & Yes & Yes \\
\hline $\begin{array}{l}\text { EORTC } \\
\text { QLQ-C30 } \\
{[24]}\end{array}$ & $\begin{array}{l}0.084 \% \text { of missing items } \\
\text { per questionnaire }\end{array}$ & No & NR & NR & NR \\
\hline $\begin{array}{r}\text { ESAS } \\
{[28]}\end{array}$ & $\begin{array}{l}\text { One non-response item of } \\
\text { out } 249 \text { questionnaires }\end{array}$ & No & Yes & NR & NR \\
\hline
\end{tabular}

$N R$ not reported

${ }^{a}$ Except for item 14 ('satisfaction with sexual life'), which had $45 \%$ of non-response rate and was removed from the analysis

Exploratory factor analysis showed that the MDASI Symptoms module had four factors, while the Interference module had a one-factor structure. The latter factor explained $49.9 \%$ of the variance, thus receiving a negative result (slightly below the set criteria of 50\%). There was evidence for a negative result in internal consistency (Cronbach's alpha $<0.70$ in all factors identified in the MDASI Symptoms module).

\section{SF-36 [27]}

The CCA methodology received a range of different quality rates [35]. Synthesis and back-translation were positive, while pretesting was negative due to the pilot test sample size (20 subjects). Questionable quality was scored for forward translation and expert committee review. No information about the submission stage was provided.

The methodological quality rate of the measurement properties assessed was poor or fair. Internal consistency assessment methodology was poor because the authors did not provide evidence for unidimensionality of the (sub)scales. The lack of a priori hypothesis about changes in scores made the methodological quality of responsiveness analysis poor.
Indeterminate results were observed in measurement error (minimal important change not defined). Evidence for a negative result was observed in hypothesis testing ( $r<0.50$ between the scales of the SF-36 and similar scales of FACT-B +4 ) and reliability (four dimensions with $\left.\mathrm{ICC}_{1,2}<0.7\right)$. Ceiling and floor effects have been detected.

\section{VES-13 [30]}

The quality of the CCA process was questionable due to lack of information about synthesis and submission process and doubtful forward translation, back-translation and expert review committee stages [33].

A range of different rates was observed for the methodological quality of the validation study. Excellent quality was observed for content validity, while convergent and divergent validity methodology (hypothesis testing) was poor due to inadequate description of comparator instruments. Poorly described missing scores made the methodological quality of structural validity and reliability fair.

Principal component analysis indicated that the VES-13 has a three-factor structure, which explained $72.6 \%$ of 
Table 5 Generalisability of included studies ${ }^{\mathrm{a}}$

\begin{tabular}{|c|c|c|c|c|c|}
\hline Instrument & $\begin{array}{l}\text { Age (years, } \\
\text { mean } \pm \text { SD) } \\
\text { Gender } \\
(\text { Male } \%)\end{array}$ & Setting & Cancer stage (TNM) & $\begin{array}{l}\text { Disease } \\
\text { status }\end{array}$ & Treatment \\
\hline $\begin{array}{l}\text { FACT-G } \\
{[26]}\end{array}$ & $\begin{array}{l}53.3 \pm 13.0 \\
38.5 \%\end{array}$ & $\begin{array}{l}\text { Outpatient } \\
\text { Inpatient }\end{array}$ & I-IV & Active & $\begin{array}{l}\text { CT/HT/RT/IMT/ } \\
\text { Any combination of above }\end{array}$ \\
\hline $\begin{array}{l}\text { MDASI } \\
\text { [29] }\end{array}$ & $\begin{array}{l}61.5 \pm 14.9 \\
35.8 \%\end{array}$ & Outpatient & III and IV: $51.8 \%^{\mathrm{b}}$ & Active & CT/RT/surgery \\
\hline $\begin{array}{l}\text { VES-13 } \\
\text { [30] }\end{array}$ & $\begin{array}{l}71.6 \pm 0.4 \\
61.6 \%\end{array}$ & Outpatient & NR & NR & NR \\
\hline $\begin{array}{l}\text { EORTC QLQ-C-15- } \\
\text { PAL } \\
{[25]}\end{array}$ & $\begin{array}{l}57.5 \pm \mathrm{NR} \\
45.1 \%\end{array}$ & Outpatient & IV & Active & $\begin{array}{l}\text { CT/surgery were cited as the } \\
\text { 'most common' used }\end{array}$ \\
\hline $\begin{array}{l}\text { SF-36 and WHOQOL- } \\
\text { bref } \\
{[27]^{c}}\end{array}$ & $\begin{array}{l}49.2 \pm 9.6 \\
\text { NA }\end{array}$ & Outpatient & IV: $24.5 \%^{\mathrm{b}}$ & NR & CT/HT/RT/surgery \\
\hline $\begin{array}{l}\text { EORTC QLQ-C30 } \\
{[24]}\end{array}$ & $\begin{array}{l}57 \pm 13 \\
41.7 \%\end{array}$ & NR & NR & NR & CT/exclusive palliative care \\
\hline $\begin{array}{r}\text { ESAS } \\
{[28]}\end{array}$ & $\begin{array}{l}55.1 \pm 12.6 \\
36.5 \%\end{array}$ & $\begin{array}{l}\text { Outpatient } \\
\text { Inpatient }\end{array}$ & $\begin{array}{l}\text { "Advanced" and stage IV: } \\
87.6 \%\end{array}$ & Active & $\begin{array}{l}\mathrm{CT} / \mathrm{RT} / \mathrm{exclusive} \text { palliative } \\
\text { care }\end{array}$ \\
\hline
\end{tabular}

$C T$ chemotherapy, $H T$ hormonal therapy, IMT immunotherapy, $N A$ not applicable, $N R$ not reported, $R T$ radiotherapy

${ }^{a}$ All authors used the convenience sample method, except for Paiva et al. [24] and Nunes [25] (both not reported)

$\mathrm{b}$ The relative percentages of other stages were not reported

${ }^{\mathrm{c}}$ Female breast cancer population

Table 6 Cross-cultural adaptation quality of generic and cancer-related Brazilian Portuguese PROMs applied for use with cancer patients

\begin{tabular}{|c|c|c|c|c|c|c|c|}
\hline Instrument & $\begin{array}{l}\text { Pilot test sample } \\
(N)\end{array}$ & $\begin{array}{l}\text { Forward } \\
\text { translation }\end{array}$ & Synthesis & $\begin{array}{l}\text { Back- } \\
\text { translation }\end{array}$ & $\begin{array}{l}\text { Expert committee } \\
\text { review }\end{array}$ & Pretesting & Submission \\
\hline FACT-G ${ }^{\mathrm{a}}[34]$ & 32 & + & + & $?$ & $?$ & + & $?$ \\
\hline ESAS [28] & 24 & + & $?$ & + & + & - & $?$ \\
\hline EORTC QLQ-C30ª [36] & $\mathrm{NR}^{\mathrm{b}}$ & $?$ & $?$ & + & + & - & + \\
\hline $\mathrm{SF}-36^{\mathrm{a}}[35]$ & 20 & $?$ & + & + & $?$ & - & 0 \\
\hline VES-13 ${ }^{\mathrm{a}}[33]$ & 33 & $?$ & 0 & $?$ & $?$ & + & 0 \\
\hline $\operatorname{MDASI}^{\mathrm{a}}[32]$ & NR & $?$ & $?$ & $?$ & $?$ & 0 & $?$ \\
\hline $\begin{array}{l}\text { EORTC QLQ-C-15-PAL } \\
\text { [25] }\end{array}$ & NR & $?$ & 0 & $?$ & - & $?$ & 0 \\
\hline WHOQOL-bref [27] & Unavailable data & & & & & & \\
\hline
\end{tabular}

$N R$ not reported

${ }^{a}$ Cross-cultural adaptation and measurement properties assessment of the instrument involved two separate publications

${ }^{\mathrm{b}}$ Sample size was not reported. However, the EORTC quality of life translation manual recommends 10 to 15 subjects as a general rule [36]

sample variance (positive result). Reliability results were also rated positive (ICC for total VES-13 scores $=0.78$ ).

\section{WHOQOL-bref [27]}

The CCA methodology was not reported.

The methodological quality rate of measurement properties was identical to the SF-36 (both tools were evaluated in the same study).
There was evidence for a positive result in hypothesis testing ( $r=0.61$ to 0.69 with similar scales of FACT$\mathrm{B}+4)$ and reliability $\left(\mathrm{ICC}_{1,2}=0.76\right.$ to 0.87$)$. Indeterminate results were observed in measurement error (minimal important change not defined). There have been no ceiling or floor effects.

Overall, the quality of the CCA was variable across studies. The methodological quality of studies evaluating Brazilian Portuguese PROMs was mostly poor or fair, 


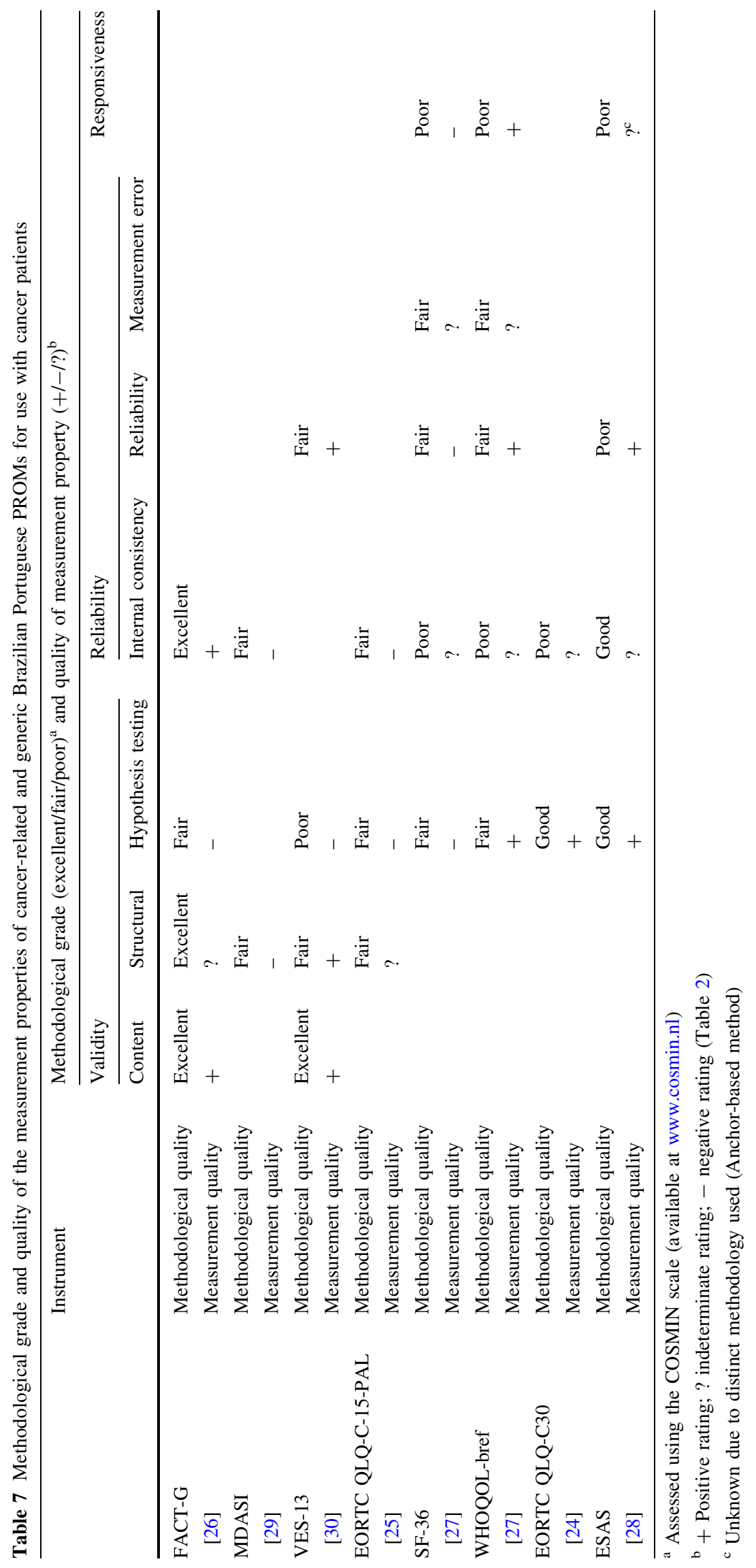


therefore limiting the evidence for the results of measurement properties. Content validity and measurement error were the least assessed measurement properties.

\section{Discussion}

The number of HR-PROMs and their culturally and linguistically adapted versions has dramatically increased worldwide in recent years. This study aimed to synthesise the literature regarding CCA quality and measurement properties of cancerrelated or generic, Brazilian Portuguese-adapted PROMs for use with cancer patients. The CCA quality throughout the eight identified instruments was inconsistent. Limited methodological quality was observed, thus compromising the measurement properties of the PROMs.

The majority of the identified instruments could be applied to adult cancer patients in Brazil. However, two instruments (SF-36 and WHOQOL-bref) were evaluated only in female breast cancer patients [27].

Interpretability refers to 'what the scores (or changes in scores) on an instrument mean' [38] and is key for the accurate use of PROMs. The interpretability of included studies was hampered as most of the authors have not reported relevant information. Bias in the validation of tools is therefore possible due to the limited description of missing scores. Underreporting of the highest and lowest scores for most instruments similarly impacted negatively on reliability and responsiveness. An adequate report on the distribution of scores of the tool, floor and ceiling effects and minimal important change would all enhance the interpretability of scores.

A wealth of methodologies regarding the CCA of HRPROMs exist. A literature review identified 17 methods of CCA [39] and recently Epstein et al. reported $31 \mathrm{CCA}$ methodologies in a review [8]. Both studies could not establish a gold standard due to the lack of comparative evidence to support one method over another. Recommendations published by Guillemin et al. [6], and refined by Beaton et al. [16], offer a thorough approach to the CCA process and have been applied in systematic reviews of HR-PROMs [10, 14, 40].

A questionable CCA has been observed mainly for the forward translation, back-translation and expert committee review steps. Although apparently counter-intuitive, forward translation and back-translation can receive distinct marks as the CCA steps keep some independence between them when assessed by the methodology selected. There is evidence for methodological inconsistency between studies. For example, while the CCA of the EORTC QLQ-C30 followed the standard EORTC translation procedure (Koller et al. [36], updated by Kulis et al. [41]), the adaptation approach of the EORTC QLQ-C15-PAL (reported by Nunes et al.) differed from the EORTC QoL Group recommendations [25]. The quality of the CCA can be improved through a careful selection of forward translators, a synthesis stage, an expert committee composed of health professionals, translators and possibly patients' representatives with clear description of their roles, piloting the tool with an ideal sample size (30-40 subjects [16]) and close involvement of developers from the original tool. Future cultural adaptations of PROMs to Brazilian Portuguese should provide sufficient information to permit full quality assessments.

$\mathrm{CCV}$ looks for equivalence of scores between source and target population and is an important aspect of PROMs' performance across cultural groups. Nevertheless, none of the included studies assessed the cross-cultural validity of instruments.

Systematic reviews of clinical trials traditionally stress the methodological appraisal of studies. Likewise, to evaluate the methodological quality of studies assessing HR-PROMs is vital as a well-conducted study on measurement properties leads to reliable results. Different criteria have been proposed to assess the methodological quality of a study's measurement properties [42-45]. The COSMIN is a consensus-based checklist covering the methodological quality of studies on measurement properties, clearly separating it from the evaluation of the PROM [46]. It provides a scoring system for each measurement property that facilitates direct comparisons between studies [18]. Nevertheless, the checklist does not make clear distinctions between limited methodological quality and poor reporting. Hence, the reasons for poor and fair methodological quality were described in the Results section of this paper for each measurement criterion.

Evidence for positive results on measurement properties with excellent or good methodology was uncommon (17.2\%) among studies. The included studies shared similar methodological deficiencies. Methodological aspects that should be improved include the formulation of detailed a priori hypothesis (including the magnitude and direction of expected scores and changes) and good description of comparator instruments, adequate description of missing scores, similar conditions and a reasonable time interval between tests in studies of reliability and measurement error and evaluation of dimensionality in internal consistency analysis.

There is no preferred method to evaluate the performance of HR-PROMs. Terwee et al. have proposed a quality assessment method for measurement properties of HR-PROMs [22], emphasising objective standards that are often lacking in alternative criteria (such as those presented by McDowell and Jenkinson [47]).

None of the PROMs included in this review had all their measurement properties assessed by the papers that evaluated them, and only two had more than half of the measurement properties reported. 
The methodological shortcomings observed and the lack of information for some measurement properties limit the applicability of this review. Most importantly, the study results indicate judicious use of any particular tool. Before any definite recommendation or guideline about the "best" tool can be made, the aforementioned improvements in the quality of the CCA and in the methodological aspects of the adapted PROMs should be addressed. Considering the particular qualities and weaknesses of each instrument, our opinion is that the FACT-G version could be recommended for QoL assessment due to the overall excellent methodology (including content validity) and the mostly positive results of its measurement properties. The EORTC QLQC30 and QLQ-C15 would be less appropriate to use due to only one positive result among five measurement properties assessed for both instruments (hypothesis testing for EORTC QLQ-C30). For symptom evaluation, the methodological quality and results for measurement properties of MDASI and ESAS were highly variable. Nevertheless, ESAS was more extensively evaluated than MDASI. Moreover, ESAS received two positive results of its measurement properties, while MDASI received negative results for all the properties studied. The VES-13 has a specific population and purpose and should be used accordingly. There is less evidence supporting the use of the SF-36. Poor to fair methodology, negative results in most measurement properties and floor and ceiling effects were observed. Finally, the WHOQOL-bref could not be fully evaluated due to the lack of information about the CCA even after personal contact with the authors.

There are several limitations to this review. The systematic search strategy, albeit thorough, may not have identified all suitable studies. The authors were unable to obtain data regarding the CCA from one of the tools (WHOQOL-bref). The quality analysis of studies reporting on measurement properties has been a topic of continuing debate. Although no gold standard is currently recognised, the methodological quality of the identified studies and the quality of measurement properties were not appraised by any alternative method in this systematic review. The same is true for the CCA analysis. Furthermore, the COSMIN checklist, although widely used, has previously shown limited inter-rater reliability in a validation study [48]. Finally, the potential policy implications of the results were not discussed and could be the focus of future studies.

\section{Conclusion}

This systematic review assessed the availability, CCA quality and measurement properties of Brazilian Portuguese generic PROMs used in the cancer population and cancer-related instruments, aiming at supporting researchers and health practitioners in the selection of questionnaires that suit their particular needs. The critical appraisal of the linguistically and culturally adapted PROMs for use in cancer patients in Brazil indicates limitations to the methodologies used for CCA, and there is limited evidence regarding the quality of their measurement properties. Considering the caveats, we suggest that the adapted FACT-G version could be used for QoL assessments, while the MDASI would be an appropriate tool for symptom evaluation. This review stressed the importance of a systematic approach towards the CCA and the need for consistent adherence to recommended guidelines for robustly developing and adequately testing adapted PROMs.

Acknowledgements Carlos Augusto extends his heartfelt thanks to Chevening Scholarships, the United Kingdom government's global scholarship programme, funded by the Foreign and Commonwealth Office (FCO) and partner organisations, for supporting the improvement of palliative and cancer care in Brazil.

\section{Compliance with ethical standards}

Conflict of interest All the authors declare that they have no conflicts of interest.

Ethical approval This article does not contain any studies with human participants or animals performed by any of the authors.

Open Access This article is distributed under the terms of the Creative Commons Attribution 4.0 International License (http://crea tivecommons.org/licenses/by/4.0/), which permits unrestricted use, distribution, and reproduction in any medium, provided you give appropriate credit to the original author(s) and the source, provide a link to the Creative Commons license, and indicate if changes were made.

\section{References}

1. Black, N. (2013). Patient reported outcome measures could help transform healthcare. BMJ. doi:10.1136/bmj.f167. (Online).

2. Instituto Brasileiro de Geografia e Estatística IBGE. (2014). Projeção da população do Brasil por sexo e idade para o período 2000-2060. https://www.ibge.gov.br/Tabuas_Completas_de_ Mortalidade/Tabuas_Completas_de_Mortalidade_2014/notaste cnicas.pdf. Retrieved 25 January 2016.

3. Instituto Nacional do Câncer INCA. (2016). Estimativa 2016: Incidência de Câncer no Brasil (Coordenação de Prevenção $e$ Vigilância). Rio de Janeiro: Instituto Nacional de Câncer José Alencar Gomes da Silva.

4. Bowling, A. (2001). Health-related quality of life: Conceptual meaning, use and measurement. In A. Bowling (Ed.), Measuring disease: A review of disease-specific quality of life measurement scales (2nd ed., pp. 1-22). Buckingham: Open University Press.

5. Cappelleri, J. C., Zou, K. H., Bushmakin, A. G., Alvir, J. M. J., Alemayehu, D., \& Symonds, T. (2014). Introduction to patientreported outcomes. In J. C. Cappelleri, K. H. Zou, A. G. Bushmakin, J. M. J. Alvir, D. Alemayehu, \& T. Symonds (Eds.), Patient-reported outcomes: Measurement, implementation and 
interpretation (1st ed., pp. 1-16). Boca Raton: Chapman \& Hall/ CRC biostatistics series, CRC Press.

6. Guillemin, F., Bombardier, C., \& Beaton, D. (1993). Cross-cultural adaptation of health-related quality of life measures: Literature review and proposed guidelines. Journal of Clinical Epidemiology, 46(12), 1417-1432.

7. Oliveira, I. S., Costa, L. C. M., Fagundes, F. R. C., \& Cabral, C. M. N. (2014). Evaluation of cross-cultural adaptation and measurement properties of breast cancer-specific quality-of-life questionnaires: A systematic review. Quality of Life Research, 24(5), 1179-1195. doi:10.1007/s11136-014-0840-3.

8. Epstein, J., Santo, R. M., \& Guillemina, F. (2015). A review of guidelines for cross-cultural adaptation of questionnaires could not bring out a consensus. Journal of Clinical Epidemiology, 68(4), 435-441.

9. Mokkink, L. B., Terwee, C. B., Patrick, D. L., Alonso, J., Stratford, P. W., Knol, D. L., et al. (2010). The COSMIN study reached international consensus on taxonomy, terminology, and definitions of measurement properties for health-related patientreported outcomes. Journal of Clinical Epidemiology, 63(7), 737-745. doi:10.1016/j.jclinepi.2010.02.006.

10. Al Sayah, F., Ishaque, S., Lau, D., \& Johnson, J. A. (2012). Health related quality of life measures in Arabic speaking populations: A systematic review on cross-cultural adaptation and measurement properties. Quality of Life Research, 22(1), 213-229. doi:10.1007/s11136-012-0129-3.

11. Crystal, D. (2010). The Cambridge encyclopedia of language (3rd ed.). Cambridge: Cambridge University Press.

12. Margolis, M. L. (2013). Goodbye, Brazil: Émigrés from the Land of Soccer and Samba. Madison: University of Wisconsin Press.

13. MacDermid, J. C., Law, M., \& Michlovitz, S. L. (2014). Outcome measurement in evidence-based rehabilitation. In M. Law \& J. C. MacDermid (Eds.), Evidence-based rehabilitation: A guide to practice (pp. 65-104). Thorofare, NJ: Slack Incorporated.

14. Puga, V. O., Lopes, A. D., \& Costa, L. O. (2012). Assessment of cross-cultural adaptations and measurement properties of selfreport outcome measures relevant to shoulder disability in Portuguese: A systematic review. Revista Brasileira de Fisioterapia, 16(2), 85-93.

15. Terwee, C. B., Jansma, E. P., Riphagen, I. I., \& de Vet, H. C. W. (2009). Development of a methodological PubMed search filter for finding studies on measurement properties of measurement instruments. Quality of Life Research, 18(8), 1115-1123.

16. Beaton, D. E., Bombardier, C., Guillemin, F., \& Ferraz, M. B. (2000). Guidelines for the process of cross-cultural adaptation of self-report measures. Spine, 25(24), 3186-3191.

17. Mokkink, L. B., Terwee, C. B., Knol, D. L., Stratford, P. W., Alonso, J., Patrick, D. L., et al. (2010). The COSMIN checklist for evaluating the methodological quality of studies on measurement properties: A clarification of its content. BMC Medical Research Methodology, 10(22), 1-8. doi:10.1186/1471-2288-1022.

18. Terwee, C. B., Mokkink, L. B., Knol, D. L., Ostelo, R. W. J. G., Bouter, L. M., \& Vet, H. C. W. (2011). Rating the methodological quality in systematic reviews of studies on measurement properties: A scoring system for the COSMIN checklist. Quality of Life Research, 21(4), 651-657. doi:10.1007/s11136-011-9960-1.

19. Baumann, F., Popp, D., Müller, K., Müller, M., Schmitz, P., Nerlich, M., et al. (2016). Validation of a German version of the International Hip Outcome Tool 12 (iHOT12) according to the COSMIN checklist. Health \& Quality of Life Outcomes, 14(3), 1-10. doi:10.1186/s12955-016-0407-9.

20. Abma, F. I., van der Klink, J. J., Terwee, C. B., Amick, B. C., 3rd, \& Bultmann, U. (2012). Evaluation of the measurement properties of self-reported health-related work-functioning instruments among workers with common mental disorders. Scandinavian
Journal of Work, Environment \& Health, 38(1), 5-18. doi:10. 5271/sjweh.3190.

21. Conijn, A. P., Jens, S., Terwee, C. B., Breek, J. C., \& Koelemay, M. J. W. (2015). Review: Assessing the quality of available patient reported outcome measures for intermittent claudication: A systematic review using the COSMIN checklist. European Journal of Vascular and Endovascular Surgery, 49, 316-334. doi:10.1016/j.ejvs.2014.12.002.

22. Terwee, C. B., Bot, S. D. M., de Boer, M. R., van der Windt, D. A. W. M., Knol, D. L., Dekker, J., et al. (2007). Quality criteria were proposed for measurement properties of health status questionnaires. Journal of Clinical Epidemiology, 60(1), 34-42. doi:10.1016/j.jclinepi.2006.03.012.

23. Schellingerhout, J. M., Heymans, M. W., Verhagen, A. P., de Vet, H. C., Koes, B. W., \& Terwee, C. B. (2011). Measurement properties of translated versions of neck-specific questionnaires: a systematic review. BMC Medical Research Methodology, 11, 87. doi:10.1186/1471-2288-11-87.

24. Paiva, C. E., Carneseca, E. C., Barroso, E. M., de Camargos, M. G., Alfano, A. C., Rugno, F. C., et al. (2014). Further evaluation of the EORTC QLQ-C30 psychometric properties in a large Brazilian cancer patient cohort as a function of their educational status. Supportive Care in Cancer, 22(8), 2151-2160. doi:10. 1007/s00520-014-2206-3.

25. Nunes, N. A. (2014). The quality of life of Brazilian patients in palliative care: Validation of the European Organization for Research and Treatment of Cancer Quality of Life Questionnaire Core 15 PAL (EORTC QLQ-C15-PAL). Supportive Care in Cancer, 22(6), 1595-1600. doi:10.1007/s00520-014-2119-1.

26. Campos, J. A. D. B., Spexoto, M. C. B., Serrano, S. V., \& Maroco, J. (2016). Psychometric characteristics of the Functional Assessment of Cancer Therapy-General when applied to Brazilian cancer patients: A cross-cultural adaptation and validation. Health and Quality of Life Outcomes, 14(8), 1-10. doi:10.1186/ s12955-015-0400-8.

27. Oliveira, I. S., Costa, L. C. M., Manzoni, A. C. T., \& Cabral, C. M. N. (2014). Assessment of the measurement properties of quality of life questionnaires in Brazilian women with breast cancer. Brazilian Journal of Physical Therapy, 18(4), 372-383. doi:10.1590/bjpt-rbf.2014.0045.

28. Paiva, C. E., Manfredini, L. L., Paiva, B. S. R., Hui, D., \& Bruera, E. (2015). The Brazilian version of the Edmonton Symptom Assessment System (ESAS) is a feasible, valid and reliable instrument for the measurement of symptoms in advanced cancer patients. PLoS ONE, 10(7), e0132073. doi:10.1371/journal.pone. 0132073.

29. Kolankiewicz, A. C., Domenico, E. B., Lopes, L. F., \& Magnago, T. S. (2014). Portuguese validation of the symptom inventory of the M.D. Anderson Cancer Center. Revista Da Escola de Enfermagem da USP, 48(6), 999-1005. doi:10.1590/S0080623420140000700006.

30. Luz, L. L., Santiago, L. M., Silva, J. F., \& Mattos, I. E. (2015). Psychometric properties of the Brazilian version of the Vulnerable Elders Survey-13 (VES-13). Cadernos de Saude Publica, 31(3), 507-515.

31. de Vet, H. C. W., Terwee, C. B., Mokkink, L. B., \& Knol, D. L. (2011). Validity. In H. C. W. de Vet, C. B. Terwee, L. B. Mokkink, \& D. L. Knol (Eds.), Measurement in medicine (1st ed., pp. 181-191). Cambridge: Cambridge University Press.

32. Ferreira, K. A. S. L., William, W. N., Jr., Mendonza, T. R., Kimura, M., Kowalski, L. P., Rosenthal, D. I., et al. (2008). Translation of the M.D. Anderson Symptom Inventory-Head and neck module (MDASI-H\&N) to Brazilian Portuguese. Revista brasileira de cirurgia de cabeça e pescoço, 37(2), 109-113.

33. Luz, L. L., Santiago, L. M., Silva, J. F., \& Mattos, I. E. (2013). First stage of the cross-cultural adaptation of the instrument The 
Vulnerable Elders Survey (VES-13) to Portuguese. Cadernos de Saude Publica, 29(3), 621-628.

34. Eremenco, S. L., Cella, D., \& Arnold, B. J. (2005). A comprehensive method for the translation and cross-cultural validation of health status questionnaires. Evaluation and the Health Professions, 28(2), 212-232.

35. Ciconelli, R. M., Ferraz, M. B., Santos, W., Meinão, I., \& Quaresma, M. R. (1999). Brazilian-Portuguese version of the SF36. A reliable and valid quality of life outcome measure. Revista Brasileira de Reumatologia, 39(3), 143-150.

36. Koller, M., Aaronson, N. K., Blazeby, J., Bottomley, A., Dewolf, L., Fayers, P., et al. (2007). Translation procedures for standardised quality of life questionnaires: The European Organisation for Research and Treatment of Cancer (EORTC) approach. European Journal of Cancer, 43(12), 1810-1820. doi:10.1016/j. ejca.2007.05.029.

37. Cortina, J. M. (1993). What is coefficient alpha? An examination of theory and applications. Journal of Applied Psychology, 78(1), 98-104.

38. de Vet, H. C. W., Terwee, C. B., Mokkink, L. B., \& Knol, D. L. (2011). Interpretability. In H. C. W. de Vet, C. B. Terwee, L. B. Mokkink, \& D. L. Knol (Eds.), Measurement in medicine (1st ed., pp. 227-274). Cambridge: Cambridge University Press.

39. Acquadro, C., Conway, K., Hareendran, A., \& Aaronson, N. (2008). Literature review of methods to translate health-related quality of life questionnaires for use in multinational clinical trials. Value in Health, 11(3), 509-521. doi:10.1111/j.1524-4733. 2007.00292.x.

40. Costa, L. C. M., Maher, C. G., McAuley, J. H., \& Costa, L. O. P. (2009). Review Article: Systematic review of cross-cultural adaptations of McGill Pain Questionnaire reveals a paucity of clinimetric testing. Journal of Clinical Epidemiology, 62, 934-943. doi:10.1016/j.jclinepi.2009.03.019.

41. Kulis, D., Bottomley, A., Velikova, G., Greimel, E., \& Koller, M. (2016). EORTC quality of life group translation procedure (4th ed.). Brussels: EORTC.
42. Alla, S., Sullivan, S. J., Hale, L., \& McCrory, P. (2009). Selfreport scales/checklists for the measurement of concussion symptoms: a systematic review. British Journal of Sports Medicine, 43(3), i3-i12. doi:10.1136/bjsm.2009.058339.

43. Lohr, K. N. (2002). Assessing health status and quality-of-life instruments: Attributes and review criteria. Quality of Life Research, 11(3), 193-205.

44. Marinus, J., Ramaker, C., van Hilten, J. J., \& Stiggelbout, A. M. (2002). Health related quality of life in Parkinson's disease: A systematic review of disease specific instruments. Journal of Neurology, Neurosurgery and Psychiatry, 72(2), 241-248. doi:10.1136/jnnp.72.2.241.

45. Valderas, J. M., Ferrer, M., Mendívil, J., Garin, O., Rajmil, L., Herdman, M., et al. (2008). Development of EMPRO: A tool for the standardized assessment of patient-reported outcome measures. Value in Health, 11(4), 700-708. doi:10.1111/j.1524-4733. 2007.00309.x.

46. Mokkink, L. B., Terwee, C. B., Patrick, D. L., Alonso, J., Stratford, P. W., Knol, D. L., et al. (2010). The COSMIN checklist for assessing the methodological quality of studies on measurement properties of health status measurement instruments: an international Delphi study. Quality of Life Research, 19(4), 539-549. doi:10.1007/s11136-010-9606-8.

47. McDowell, I., \& Jenkinson, C. (1996). Development standards for health measures. Journal of Health Services Research \& Policy, 1(4), 238-246.

48. Mokkink, L. B., Terwee, C. B., Gibbons, E., Stratford, P. W., Alonso, J., Patrick, D. L., et al. (2010). Inter-rater agreement and reliability of the COSMIN (Consensus-based Standards for the selection of health status Measurement Instruments) checklist. BMC Medical Research Methodology, 10, 82. doi:10.1186/14712288-10-82. 